\title{
Formation of the resource saving process in commercial property buildings during the introduction of "green" standards in Russia
}

\author{
Anna Gurko ${ }^{1, *}$ \\ ${ }^{1}$ Moscow State University of Civil Engineering, 109377, 26 Yaroslavskoye Shosse, Moscow, Russia
}

\begin{abstract}
The article is dedicated to one of the most essential areas in the construction industry: consideration of the issues related to resource saving, ecologically and economically rational use of natural resources in accordance with "green standards" of the commercial property buildings, offices, in particular. During the operation of office buildings there takes place negative impact on all the components of the environment. Herewith, the first issues considered by the operating organizations are the cost of the facility, safety of technological processes, reliability, durability and operational characteristics, and only then the issues of building environmental friendliness and energy efficiency, the consequences of which are irrational use of natural resources and accumulation of environmental damage. The number of existing systems certifying "green" buildings is insufficient to create a stable human environment. Formation of the resource saving mechanism during the operation of office buildings requires the application of the "green" standards criteria, making it possible to provide results of the stable approaches during the entire operational lifetime of the building. Based on the local and foreign experience in resource saving stimulation under the "green standards" the article provides the estimation criteria making it possible to implement the ecological and economic evaluation of the resource saving mechanism during the operation of office buildings.
\end{abstract}

\section{Introduction}

Green construction dates back to the $70 \mathrm{~s}$ of the past centuries, when the idea of conservation and ethic attitude towards natural resources became popular.

The so-called "green construction" was the result of ecologists and architects' unification $[1,2]$.

"Green construction is the area including the construction and operation of the buildings with minimal impact on the environment. The main task of green construction is to reduce the level of energy and materials consumption during the entire operational life of the building: from the selection of the site till the design, construction, operation and demolition."

\footnotetext{
*Corresponding author: ai_gurko@mail.ru
} 
During the modern stage of the construction industry development, real estate has low energy efficiency, still having great potential in energy consumption efficiency. The main reason for these problems is the absence of a unified tool regulating and controlling resource consumption and, consequently, the absence of the stimulus to implement the required measures. Nowadays, the construction and operation of the objects under "green" standards become the most efficient way of introduction and verification of the solutions for resource saving, ecologically and economically rational use of natural resources.

Consideration and analysis of the existing systems for "green" buildings certification has revealed that they do not reflect the peculiarity of resource saving organization during the operation of the facility, which leads to low energy efficiency of the buildings, irrational use of natural resources and accumulation of the environmental damage. During the stage of operation, referring to the office buildings, the process of resource saving is first of all aimed at the establishment of such a level of resources consumption, when there is kept a comfortable human environment and the increase of the quality of the very building. The ecological component fades into insignificance.

The analysis of the pieces of work dedicated to this topic makes it possible to conclude that the existing resource saving processes are mainly based on the technological basis. Herewith, there is no sufficient attention paid to the possibility of forming an effective resource saving mechanism based in the "green" standards which regulate the stable approach in the area of construction at the stage of buildings and facilities operation $[4,5]$.

That is why the aim of this research is the development, justification and application of a complex criteria system, making it possible to form a resource saving mechanism for office buildings and facilities, providing their stable functioning by reaching ecological rationality.

This paper has the following abbreviations:

BREEAM BRE- Environmental Assessment Method;

LEED - Leadership in Energy and Environmental Design;

DGNB - Deutsche Gesellschaft für Nachhaltiges Bauen - German Council for Stable Construction;

SAR-SPZS - Voluntary Certification System "Evaluation of environment sustainability" Union of Russian Architects - Green Building Council.

STO NOSTROY 2.35.4-2011 - Russian standard establishing the ranking system for evaluation of the environment sustainability.

EcoVillage system of voluntary ecological certification of cottage settlements.

\section{Materials and Methods}

For the first time, within the UNO conference on environment and development, which took place in 1992 in Rio de Janeiro, humanity recognized the necessity of the world, countries and cities in stable development, and specialists: urban planners, architects and builders came to the solution on the possibility of stable design and construction of the cities aimed, first of all, at the principles of energy efficiency, which could support their stable development $[2,5]$.

One of the sources of inefficient resource consumption in the modern world is the stage of operation of different purpose facilities, office buildings, in particular. The process of offices operation has a massive negative impact on the ecosystems, both direct and indirect: extraction and exhaustion of natural resources (raw materials, oil, water, land resources), air pollution, water pollution, impact on subsoil water, waste accumulation, damage to natural landscapes, appearance of solid waste, increase on the anthropogenic load on the territory, etc. The increase of the negative impact on the nature and the increasing growth rates are 
the main problems for the cities, especially for large Russian agglomerations. Due to this, environmental aspects pay ever-greater role.

In the modern Russia about $20 \%$ of all energy resources are given to heat and maintain buildings, $90 \%$ of the energy given for building operation is taken for heating. The greatest consumption is by residential buildings: $45-55 \%$, industrial buildings: $35-45 \%$. This amount of energy consumption is not recorded in any country of the world.

Now the world uses different resource saving tools for real estate: different programs for resource saving support, including funds and grants (Australia, China, the USA, France and Switzerland), national design and construction standards for "green" buildings (the UK, the USA, Germany, Canada, China, India and other); subsidy assistance to "green" industry (Australia, Germany and Italy). The implemented review and analysis of the foreign countries experience in the area of resource saving activity has shown that "green" construction is the effective way to improve facilities environmental friendliness $[6,7,9,11]$.

In case of intelligent approach to the design, the application of green standards will not lead to costs increase, as green standards are aimed at cost saving by building operation. To reach this saving, the building must be designed under the requirements of the green standards.

Green building is more particular about design and construction, which means additional measures and thus, extra costs.

These costs are paid off by significant saving of the monetary funds during the building operation, which is the longest stage of the building life cycle; depending on the degree of reliability and purpose of the building, it can be of one hundred or more years. This is the economic essence of green standards. According to the research, the costs for building operation can reach about 80 percent during its operation. (fig.1).

Using green standards, the saving during the operation can reach $30-40 \%$ of the monetary funds. The return on investment can be during the period from 2 to 5 years.

The effective resource saving tool during the operation of office buildings can become the resource saving mechanism, the main stages of which will be: 1. Formation of the resource saving management fundamentals in the office building. 2. Qualitative and quantitative analysis of the reasons for irrational resource consumption. 3. Determination of possible optimization of resource consumption. 4. Determination of the budget allocated for implementation of the complex resource saving program. 5. Evaluation of possibilities and restrictions. 6. Elaboration of measures and solutions. 7. Evaluation and analysis of the resource saving level, control over resource consumption. 8. Implementation of evaluation of the implemented mechanism effectiveness. 9. Evaluation and re-implementation of the measures for resource saving after a certain time period.

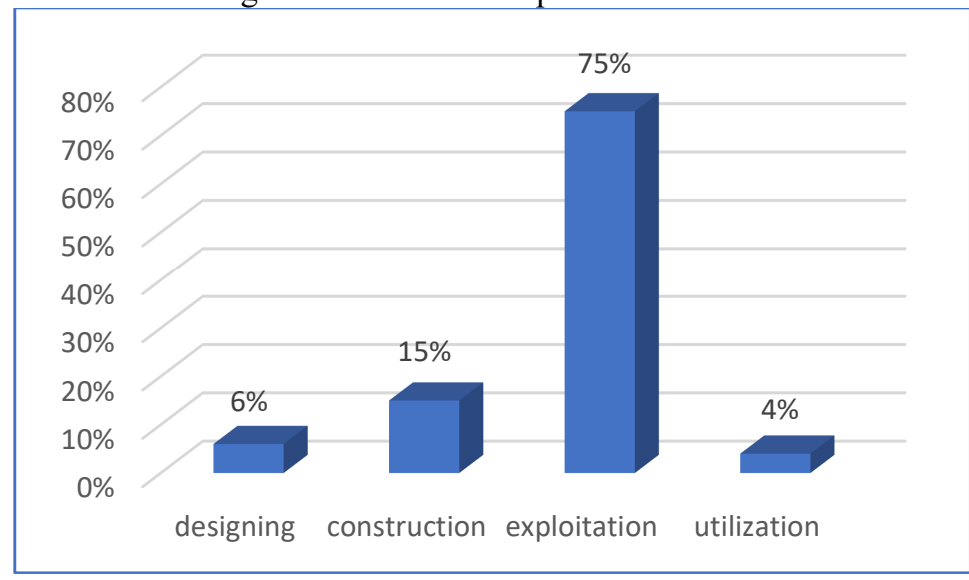

Fig. 1. Average costs during the life cycle of the building (design, construction, operation, disposal). 
In this scheme is followed the important principle of "constant improvement" which makes the basis for different modern management systems. The important advantage of this mechanism is adaptability, i.e. it is possible to implement the resource saving mechanism in offices and organizations of different purposes, with no reference to the specificity of their activity. The foundation for such mechanism formation, determination of its requirements and criteria, could be different standards of "green" building.

The Ministry of Natural Resources and Environment of Russia defines "green standards" as the construction standards applicable to new and existing facilities, which describe the conditions for the creation and operation of environmentally friendly constructions to evaluate environment efficiency of the buildings and provision of minimum pollution of the environment and high level of environmental safety for people.

The following "green" standards should be mentioned: LEED (the USA); BREEAM (the UK); DGNB (Germany) and Russian standards: Evaluation of environment sustainability SAR-SPZS; Voluntary Certification System for real estate "Green standards"; STO NOSTROY 2.35.4-2011 "Green building"; certification of environmentally friendly cottage settlements EcoVillage $[9,10]$.

The implemented analysis of the standards, made it possible to make the following conclusions:

All the seven considered standards have obligatory criteria

All standards take into account not only ecological and economical, but also social aspects

All standards support the use of innovations and the best available technology

All standards (except for Eco Village) have different versions for different types of buildings

All standards (except for Eco Village) assign the certified facility with the level admitting comparison of buildings

Only three standards (Green standard; STO NOSTROY 2.35.4-2011 "Green building"; Eco Village) admit certification of the existing building

Two standards (Evaluation of sustainability SAP-SPZS, Green standards) have government support.

International standards are the most demanded ones. However, they are not adapted to the Russian specificity, which is shown up in the ranking system of certification of "green" building, which currently does not make it possible to take into consideration the energy ratio of the buildings during the determination of the level of resource consumption.

Thus, the effective direction in transformation is the formation of the Russian mechanism of resource saving, which takes into account the specificity of the Russian building industry and provides environmental efficiency of the buildings.

Collection of the information about the main sources of resource consumption and formation of the goals make it possible to determine what are the elements for which it is possible to implement optimization of resource consumption in order to achieve the increase in the environmental rationality and appropriateness of resource saving during the operation of office buildings.

Office environmentalization makes it possible not only to decrease the negative effect on the environment, but also to improve the manufacturing environment and decrease the costs by saving natural resources.

The difficulty in evaluation of the efficiency of resource saving mechanism in the office buildings, as well as in other commercial real estate, is related to crucial difference of the requirements and the required measures for energy saving. For ones, it is possible to evaluate monetary results, for others - only to implement an expert numerical score, etc. That is why we suggest evaluating the success of resource saving mechanism implementation in office buildings according to two directions: 
Table 1. Factors of resource saving in an office building.

\begin{tabular}{|c|c|}
\hline Input flows / Resource saving factors & Output flows / Resource saving factors \\
\hline $\begin{array}{l}\text { 1. Information } \\
\text { Increase in the amount of the input information } \\
\text { referring to the protection of the environment aimed } \\
\text { at the increase of environmental awareness of the } \\
\text { facility users and attraction of the society to the issue } \\
\text { of environmental damage decrease. }\end{array}$ & $\begin{array}{l}\text { 5. Company activity results. } \\
\text { Determination of the possibilities to increase } \\
\text { the environmental friendliness of the products } \\
\text { and/or company activity results, } \\
\text { implementation of the environmental } \\
\text { component. }\end{array}$ \\
\hline $\begin{array}{l}\text { 2. Water } \\
\text { Determination of the reasons of noneffective water } \\
\text { consumption, elaboration of the measures for its } \\
\text { optimization. }\end{array}$ & $\begin{array}{l}\text { 6. Loss of heat and energy } \\
\text { Determination of the main reasons of heat and } \\
\text { energy losses, elaboration of measures for } \\
\text { their minimization. }\end{array}$ \\
\hline $\begin{array}{l}\text { 3. Machinery and equipment } \\
\begin{array}{l}\text { Determination of the possibilities to improve or } \\
\text { change the existing machinery and equipment. }\end{array}\end{array}$ & $\begin{array}{l}\text { 7. SMW } \\
\text { Elaboration of the measures for minimization } \\
\text { of SMW amount and their transfer for } \\
\text { recycling. }\end{array}$ \\
\hline $\begin{array}{l}\text { 4. Energy } \\
\text { Determination of the reasons of non-effective energy } \\
\text { consumption, elaboration of the measures for its } \\
\text { optimization. }\end{array}$ & $\begin{array}{l}\text { 8. Water loss } \\
\text { Determination of the reasons of non-effective } \\
\text { water consumption, elaboration of the } \\
\text { measures for its optimization. }\end{array}$ \\
\hline
\end{tabular}

Develop special criteria for evaluation of the effects in the following groups:

1. Indices which can be evaluated in money;

2. Indices with a minimum required level;

3. Indices with expert evaluation;

Use the evaluation criteria card.

Introduction of the resource saving mechanism in office buildings cab be considered successful only in case of positive results in both variants of evaluation.

Let us consider the groups of indices which can be evaluated in money:

For example, implementation of energy saving measures, when the costs for their elaboration and introduction are known together with the saving results.

This group includes the following indices:

1.1. Energy consumption

1.2. Water consumption

The index is calculated as the ration of saving (income) from the introduction of a certain result to the costs for its creation under the formula:

$$
E=\frac{\sum P i: C i}{i}
$$


when $\mathrm{E}$ is economic efficiency; $\mathrm{Pi}$ is income (saving) of the $\mathrm{i}$ index, RUB.; Ci costs for creation of the saving of the $i$ index, RUB. The index is considered effective if $E>1$. It makes sense to evaluate the index with certain periodicity.

\subsection{The group of indices for which is established the required minimal level}

For each of the $\mathrm{Ki}$ index is established a minimum level $\mathrm{Ki}$ min, the condition is: $\mathrm{Ki} \geq \mathrm{Ki}$ $\min$.

This group includes the following indices: 2.1. Amount of the charitable funds for protection of the environment 2.2. Waste for recycling

The effect index of the $2^{\text {nd }}$ group is calculated as the arithmetic average of the actual value and the minimal under the formula"

$$
K=\frac{\sum \text { Kifact }: \text { Ki min }}{i}
$$

when $\mathrm{K}$ is the effectiveness of the 2 nd group, shares; Ki fact. - actual value of the $\mathrm{i}$ index; Ki min - minimally accepted value of the i index. The index is considered effective if $K>1$.

\subsection{The group of indices for which is implemented expert evaluation}

The third group includes the indices using which it is difficult to implement a quantitative evaluation not including the expert opinion. This group includes the following indices: 3.1. Purchases 3.2. Professional diseases 3.3. Comfort, general physical and mental state of the staff 3.4. Level of environmental responsibility

Each index is evaluated from 0 to 10 points by a group of experts. The indices 3.3 and 3.4. can be evaluated on the basis of specially elaborated questionnaires or tests. It makes sense to evaluate the purchases index in point, as their monetary value does not reflect environmental aspects, for example: more energy saving machinery can cost less. It should be noted that indices 3.2-3.4 make it possible to evaluate the effects of the mechanism with reference to people, i.e. taking into account social factors.

The passing score is 6 , i.e. the values from 0 to 5 are not acceptable. The efficiency level of the third group is calculated as the relation of the points amount to the amount of the indices and the lowest passing score of 6 , which exceeds the average value. There are accepted the variants when the point is given by expertise depending on the situation in the region and other criteria.

$$
P R=\frac{\sum A \mathrm{i} \text { fact }}{\mathrm{i} * 6}
$$

when PR is the effectiveness of the $3^{\text {rd }}$ group, share; PRi fact. value of $\mathrm{i}$ index, point; 6 passing score. The index is considered efficient if $\mathrm{PR}>1$.

System of criteria for three groups Let us unite the group indices into a big system $\{\mathrm{E} ; \mathrm{K} ; \mathrm{PR}\}$ : 


$$
\text { Кобщ }=\left\{\begin{array}{l}
E \rightarrow \text { max } \\
P \rightarrow 1 \\
E>1 \\
----- \\
\mathrm{K} \rightarrow \max \\
\text { Kifact } \geq \text { Kimin } \\
\text { Kifact } \rightarrow \text { max } \\
------ \\
\mathrm{PR} \rightarrow \max \\
\mathrm{PR}>1 \\
\mathrm{PRi} \geq 6
\end{array}\right.
$$

when $\mathrm{N}$ общ. is the index of the resource saving mechanism effectiveness in office buildings, calculated as arithmetic average or taking into account the weights assigned respectively $\mathrm{E}, \mathrm{K}, \mathrm{PR}$.

The implemented mechanism is considered effective if Nобщ. $>1$ and all the conditions are respected in each of the three groups.

It also makes sense to implement the evaluation of resource saving mechanism in office buildings using the evaluation card. The evaluation card of requirements is applicable to the office building which implements the resource saving mechanism during operation in order to evaluate the fulfillment of the requests and measures divided into different sections.

The evaluation card makes it possible to evaluate the fulfillment of the requests for resource saving under a score system. Then:

$$
T=\frac{\sum \mathrm{Rn}\left(\mathrm{N}_{д}\right)}{\mathrm{t}}
$$

when $\mathrm{T}$ is the effectiveness in accordance with the evaluation card; $t$ is the sufficient total score. Consequently, under the evaluation card, the condition of effectiveness is the implementation of the condition: $\mathrm{T} \geq 1$. The suggested scheme of evaluation makes it possible to evaluate the success and effectiveness of the resource saving mechanism implementation in office buildings.

\begin{tabular}{|c|c|c|c|c|c|}
\hline & \multicolumn{4}{|c|}{ Section N } & \multirow{3}{*}{$\begin{array}{c}\text { Obtained result } \\
(\mathrm{Rn}) \\
\mathrm{Rn}(1, \ldots \mathrm{n}) \rightarrow \\
\max \\
\end{array}$} \\
\hline & N1 & N2 & $\ldots$ & $\mathrm{Nk}$ & \\
\hline Score & \multicolumn{4}{|c|}{ "Section name" } & \\
\hline $\mathrm{Rn}$ & $\mathrm{N}_{\mathrm{n}} \mathrm{R}_{1}$ & $\mathrm{~N}_{\mathrm{n}} \mathrm{R}_{2}$ & & $\mathrm{~N}_{\mathrm{n}} \mathrm{R}_{\mathrm{k}}$ & $\mathrm{Rn}(\mathrm{Nn})$ \\
\hline 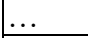 & & & & & \\
\hline R1 & $\mathrm{N}_{1} \mathrm{R}_{1}$ & $\mathrm{~N}_{1} \mathrm{R}_{2}$ & & $\mathrm{~N}_{1} \mathrm{RK}$ & $\mathrm{Rn}(\mathrm{N}$ д) \\
\hline & & & & & $\begin{array}{ll}\text { Total } & \text { of } \\
\mathrm{Rn}(\mathrm{N} \text { д) }\end{array}$ \\
\hline $\mathrm{T}$ & & & & & $\begin{array}{ll}(\text { total } & \text { of } \\
\operatorname{Rn}(\mathrm{N} /) & * 100) / \mathrm{t}\end{array}$ \\
\hline
\end{tabular}

Table 2. Criteria evaluation card for standard requirements. 


\section{Results}

In order to evaluate the effectiveness of the resource saving mechanism implementation there is a system of evaluation consisting of two directions: criteria from three groups for 8 indices required for the evaluation of the implemented mechanism; evaluation card for evaluation of the implementation of the obligatory requirements and accumulation of the points in accordance with the requirements.

For a more reasonable calculation of the final index ( $\mathrm{N}$ общ) the author suggested the mechanism of coordination under the method of hierarchies analysis - a mathematical tool of systematic approach to difficult problems of decision making.

Let us show the three elaborated groups of indices and the criteria from the evaluation cards in the form of the general system of evaluation criteria $\{$ Nобщ; T\}:

$$
Y=\left\{\begin{array}{l}
\left(N_{\text {общ }}+T\right) / 2 \\
\mathrm{~N}_{\text {общ }} \geq 1 \\
T \geq 1
\end{array}\right.
$$

When $Y>1$ the resource saving mechanism implemented during the operation of the office building is considered effective. Thus, this system simultaneously takes into consideration social, environmental and economic factors, and there is evaluated the fulfillment of the requests to resource saving.

One of the effective mechanisms of energy saving implementation in the foreign countries is the creation of a revolver fund. This experience should be approved for Russia as well. The essence of its creation is in the accumulation of the resources by the financial flows received after the implementation of fast-payback energy saving measures, and further reinvestment of these funds in other events. Such turnover of the financial funds makes it possible to significantly increase the effectiveness of their use. The selection of rational ratio between the amount of investment and the amount of the funds incoming after energy saving, makes it possible to provide continuous financial support to the energy saving program.

\section{Discussion}

Specification of the requirements for resource saving in office buildings is one of the most important tasks in the area of environmental protection. However, according to the analysis of the existing systems, certification is not enough for the creation of a stable human environment. During the formation of the resource saving mechanism when office buildings are operating, it is necessary to apply the "green" standards criteria making it possible to provide effectiveness of the stable approaches at the stage of buildings operation.

To implement this, the paper

1. has examined the Russian and foreign experience of resource saving state regulation and stimulation aimed at the Russian conditions adaptation;

2. has analyzed the factors increasing resource consumption in office buildings on the basis of the environmental criteria system;

3. has elaborated the evaluation criteria of the environmental and economic justification of the decisions during the organization of office buildings resource saving, 
and has implemented the analysis of their impact on the formation of the resource saving mechanism depending on the required level of comfort and safety of the environment.

In order to improve the environmental and economic situation in our country, it is necessary to elaborate the resource saving mechanism providing stable operation of buildings (commercial real estate, in particular) by adaptation and standardization of the resource saving principles.

\section{References}

1. C. Luangcharoenrat, S. Intrachooto, J. Architect. Plan. Res. Stud. 10, 1-18 (2013)

2. World Green Building, http://www.worldgbc.org/worldgbc/members/

3. Yudina, Technological processes in construction (2013)

4. G. Sternik, S. Sternik, N. Tulinova, Real Estate Development (2016)

5. Kang Ming, Zhang Hao. J. Build. Mater. Decor., 4(10), 23 - 24 (2010)

6. S. Kubba, Handbook of Green Building Design and Construction LEED, BREEAM, and Green Globes, 2017

7. M. Sleeuw, A comparison of BREEAM and LEED environmental assessment methods: a report to the University of East Anglia Estates and Buildings Division (2011)

8. A. Frattari, M. Dalpar, Salvaterra, J. Hous. Sci. 36(3), 138-148. (2012)

9. C. J. Kibert, Sustainable construction: green building design and delivery: John Wiley \& Sons, 2016.

10. A.R. Pearce, Y.H. Ahn, Hanmi, Global, Sustainable Buildings and Infrastructure: Paths to the Future (2012)

11. A. Gurko, S. Oparina, L. Vasyutkina, E. Potekhina, The environmental investments justification E3S Web of Conferences 91, 08029 (2019)

12. S. Beliakov, A. Kapustkina, E3S Web of Conferences 97, 01034 (2019)

13. J. Varodompun, J. Architect. Plan. Res. Stud. 1, 123-152 (2009)

14. N. Delgarm, B. Sajadi, F. Kowsary, S. Delgarm, Multi-obj. Optim. Build. Ener. Perf. Simul.-based Appr. Means Part Swarm Optim. (PSO). Appl. Ener. 170, 293-303 (2016) 